\title{
An Arabic text as content in an Indonesian EFL setting: Trans-language
}

\author{
Safi Aini \\ Esa Unggul University, Indonesia
}

Abstract: Maynard and Furlong (1995) state that teaching materials should be something that students can relate to, and that occupy students' interests. They assert that teachers must recognise what students already know about material to be learnt, and introduce teaching material which students are somewhat familiar with. This study was conducted at an Islamic school where the English teachers fostered a culture of English learning using content embedded in Islamic theme. This was manifested in Arabic textbooks, which were used as a resource for learning English, and as a basis for translation and communicative language activities. The purpose of this study is to examine learners' perceptions about the use of Arabic texts as a resource for learning English as a foreign language (EFL). The results show that through a trans-language approach, learners can improve their English vocabulary, understand parts of speech of translated English words, improve their use of English grammar, especially regarding tenses, learn how to translate, and speak English more fluently, since they understand the content of the textbooks. However, they also have difficulty in making English sentences in the passive voice, and in pronouncing English words.

Keywords: Arabic textbooks in EFL, Arabic-English translation, Islamic school, translanguage

\section{INTRODUCTION}

Learning a foreign language, with some content about the culture of the native speakers of that language, can be an advantage if the learners are from a similar culture, but can prove a burden if they are not. Although knowing the culture associated with the foreign language can enrich students' knowledge, the impact of cultural differences inhibits communication. This can become an issue in learning English as a foreign language (EFL), since the culture of English is quite distinct from cultures of some countries.

Tomlinson (2005) asserts that ELT materials for Asia should focus on pedagogic approaches that are familiar to learners in the region, matching the norms of their school and societal culture. Indeed, Maynard and Furlong (1995) argue that the teaching materials should be something that students can relate to, and within students' interests. They believe that teachers must recognise what students already know about material to be learnt, and start teaching material which students are somewhat familiar with. When students can draw upon prior knowledge to complement their learning of new knowledge, "they find it easier to 
make sense of their learning, and will be more willing to learn" (Cheung, 2001, p. 58).

This aspect relates directly to this study, which was conducted at an Islamic school where English teachers fostered a culture in which the English learning content was embedded in Islamic themes. This was manifested in the use of an Arabic textbook as a source to learn English through translating word by word, arranging the translated words, and questioning the functions of the words in the text. In translating word by word, learners looked for the meaning of Arabic words by themselves, then arranged the English translated words, based on the intended meaning of the Arabic text. The teacher corrected and discussed students' work. The last stage was a communicative language activity in which students asked each other about the position of each Arabic word in the text and related it to English, both in meaning and as a part of speech. The following is an example of the activity. The roles of questioner and respondent were afterwards switched between students A and B:

Student A: "What is the meaning and position of 'masjidin' in this sentence?" ("Masjidin' is the way the Arabic word مسجد is pronounced.)

Student B: "The meaning of masjidin is a mosque, and its position is isim in the sentence."

Student A: "What is isim?"

Student B: "Isim is a word which has a meaning. Isim is a noun, so the word masjidin is a noun."

Student A: "How do you know that the word masjidin is a noun?"

Student B: "Because the word masjidin has a suffix, $-i$, which signifies that the word is a noun in Arabic. Accordingly, mosque as the meaning of masjidin is a noun in English."

This programme provided an appealing context for this study, as it was a way of learning a foreign language by means of another foreign language already mastered. It was necessary to investigate Indonesian EFL learners' perceptions of the classroom practices that they experienced in this context. This was based on the assertion of Nunan (1993, p. 4) that "teachers should find out what their students think and feel about what they want to learn as well as how they want to learn". The research questions posed in this study asked what were the benefits and challenges of using an Arabic text as a resource in EFL learning.

\section{LITERATURE REVIEW}

Translation plays a positive role in EFL classes. It can help learners to enrich their target language vocabulary, understand how the target language works, and develop their comprehension and style in the target language, as well as reinforcing for them the structure of the target language (Schäffner, 2002). The advantages of translation are also supported by Liao (2006), who found that Taiwanese-English translation can help students to check whether their comprehension is correct. The findings also validated the notion that if students' ideas and expressions can be conveyed in another language, their anxiety can be reduced, making them more engaged in learning English. 
Similarly, Carreres (2006) investigated perceptions of 11 second- and third-year Cambridge University students about translation as a language-learning activity. The study suggested that translation is very useful, the best exercise for language learning, and to test whether students have fully understood a text. Again, Nolasco and Arthur (1995, p. 59) confirm that translation activities in an EFL classroom should meet these criteria: that language is used for a purpose; that they create a desire for communication; that they encourage students to be creative and contribute their ideas; that students focus on what they are saying, rather than on how they are saying it; that students work independently of the teacher; and that students determine what they want to say and write.

In contrast, Ali et. al (2012) identify linguistic difficulties in translation, especially from Arabic to English. These problems occur due to the semantic, alphabetical and structural differences between the two languages. For example, arranging translated words is a syntactic process - Arabic and English have their own specific syntactic pattern rules. English begins a sentence with a subject followed by a verb (Halliday et al., 2014). Conversely, Arabic sentences are formed as verb-subject-complement (Ali et al., 2012).

Moreover, translation is also widely believed to be influenced by culture. The intended meaning of the text being translated mainly relies on the culture of the source language, which, in practice, is not always represented in the target language. Zainab's research on translation (2010) revealed that inaccurate translations and mistranslations could result from cultural differences, when the words reflect an Arab cultural setting that does not exist in English. Ya'qoub (2013) demonstrated that changing words from a source language can help a translator to convey the intended meaning of a text. Not only does translation entail changing words from one language into semantic equivalence in another, it also requires the appropriation of socio-cultural elements between the two languages. In brief, an acute awareness of cultural distinctions between target and source languages is crucial.

Trans-language has been described as "the act performed by bilinguals of accessing different linguistic features or various modes of what are described as autonomous languages, to maximize communicative potential" (García, 2009, p. 140). Trans-language describes multilingual speakers' competence in conveying their message in the form of diverse languages as an integrated system. Translanguage does not refer to the language practices of two separate monolingual students who cannot understand one another; instead "trans-language" describes the practices of all students and educators who use bilingualism as a resource, rather than perceiving it as a problem. Language is employed to deliver material, while trans-language allows bilingual students to implement language practice used in academic contexts alongside their home language practices in order to learn as well as to comprehend material accurately. This can be achieved through collaborative group work with multilingual partners; such activities create opportunities for students to use their entire linguistic repertoire.

Trans-language brings many benefits to language teaching and learning. In completing lessons (Lin and Martin, 2005; Arthur \& Martin, 2006), learners are able to comprehend messages from teachers more easily, and this increases their 
motivation and participation in class, as trans-language focuses on function rather than form. Moreover, learners' meta-linguistic awareness will improve, owing to learners' acknowledgement of linguistic features when they practice several languages at the same time. Using trans-language presents learners with challenges which allow them to build bilingual strength and develop bilingual voices. A study describing a flexible bilingual approach to teaching and learning in English and Gujarati was conducted by Creese and Blackledge (2010) in the United Kingdom. It showed that the intended meaning of teachers' instructions would be unclear without trans-language between Gujarati and English; the teacher used the languages to deliver meaning, or to transmit information to engage students. In addition, the study demonstrated that trans-language Gujarati and English was employed to establish procedural knowledge in discussions and clarification, as well as in task completion.

The presence of two different languages in this study of English language learning gives rise to two major hypotheses, one linguistics interdependent and the other script-dependent. Script-dependent hypotheses are where a problem is a product of language differences (Abu-Rabia and Siegel, 2002; Abdul Haq, 1982; Zughoul, 1984). For instance, Arabic has a one-to-one relationship between its grapheme and phoneme (that is, learners can read or pronounce Arabic words as the words have been written as well as spelt), but English does not. In English, words are pronounced differently from their spellings. Indeed, a single letter in English can be pronounced differently in several words. For example, the letter "c" is spelt "si", but can be pronounced as "s" in the word "pronounced /pronaunst/" and "k" in the word "Arabic /arəblk/". Obviously, English and Arabic have distinct orthographies.

In contrast, Cummins (1979) hypothesises that learners' difficulties in learning a second language are the same as those faced in their first language. These are called linguistic interdependent hypotheses. Obstacles to learners' first language will be transferred to the acquisition of their second language. Additionally, the skills which learners master in their mother tongue are the skills in which they demonstrate strengths in the second language. Arabic-speaking learners of English who are skilful in writing will become proficient in English writing skills. Abu-Rabia and Siegel's (2002) study established that, bilingual children with reading problems in English consistently show similar problems in Arabic, and disabled readers in Arabic display the same difficulties with phonological processing as disabled readers in English. Even if distinct languages have different orthographies, learners' reading skill in the first and second languages still correlate, hence learners' difficulties in one orthography will occur in the other.

\section{RESEARCH METHOD}

Regarding the context of this study, it employed qualitative research methods, as it was aimed at building up rich, in-depth descriptions of students' experiences and perceptions. This is in line with Punch's view (2009) that through qualitative research, data about perceptions from those involved in certain activities can be collected. This research was conducted in an Islamic private school, and involved eight learners. All participants were sixteen or seventeen 
years old, and at senior high school. The researcher asked the teacher to select students with high or low scores in the programme, because the researcher wanted to analyse the challenges and advantages they face.

The questions that the researcher used in this semi-structured interview were open-ended as, according to Borg (2015), this type of question requires participants to elaborate on their answers by using their own language, and participants might happily expand their answers verbally. The interviews were carried out in the Indonesian language, as participants preferred to speak Indonesian, even though some of them initially spoke English. To assure the response validation, participants verified the researcher's transcription and interpretation.

Data analysis was divided into several phases. Interviews were recorded and transcribed before classifying repeated terms or paraphrases into common themes relating to the research questions. Hancock and Algozzine (2006) suggest that thematic analysis is often preferred, with each new piece of information examined in the light of specific research questions, in order to construct a tentative answer to these questions.

\section{FINDINGS AND DISCUSSION}

\section{Translating word-by-word activity}

\section{English vocabulary enrichment}

Analysing information gained from the interviews highlighted an evident agreement that a major benefit was vocabulary enrichment. Here are some of the students' responses:

"To make my learning easier, I looked for some unknown vocabulary. My teacher had us to look for the Arabic words which we did not understand in English by using an Arab-English dictionary. As I understood the meanings of the Arabic words, I could easily find and understand the meaning of the words in English. From this activity, I could enrich my English vocabulary."

"There is issue with vocabulary because I can use a dictionary to look for the English translations of certain Arabic words. By using this Arabic textbook, I can enrich my vocabulary, especially to many terms in Islamic law, such as 'sunnah', meaning optional, 'fardhu' meaning obligation and 'muthlak' meaning absolute.'

"My understanding of Arabic structure helped me to learn English structure. Moreover, I could learn more vocabulary, but the enrichment of my English vocabulary is restricted to the words I learn from the textbook. If I translate many Arabic textbooks, my English vocabulary will expand.' 


\section{Understanding English parts of speech}

Not only did the students know the meaning of the Arabic words in English and thereby enlarged their English vocabulary, but they could also understand the position of the English translated words, based on parts-of-speech rules. They reported that they grasped the patterns from Arabic to English. The following quotes were typical:

"In the first chapter, my teacher helped us to translate the Arabic words into English by providing the meaning of each Arabic word in English, then, for the next chapter, she asked us to do it by ourselves. When translating word by word, I thought, 'Ooh, "kalam" means a sentence in English and this word is "fi' 'il" which means verb in English, I've got it.' So, if in Arabic this word is 'isim', in English it is a noun."

"I learnt about English grammar, like tenses for two months before learning English using an Arabic theological textbook. Then, the learning activities using the Arabic theological textbook involved translating the textbook into English. From that book, I learnt what Arabic word is called by what in English, for example, fi'il (an Arabic word) in English is verb, fa'il (an Arabic word) in English is subject."

"We tried to relate each Arabic word in the text to parts of speech (noun, verb, adjective, adverb and others) in English. For instance, 'isim' (an Arabic term meaning noun in English) is a type of noun, so I related the word to English to determine that this was a plural noun in English."

"I could understand the terms in English such as noun, verb and others since I know the terms in Arabic. For instance, I understood the terms 'khobar' as well as 'mubtada' in Arabic because as far as I know, there were similar terms of these words in English, those are subject and predicate respectively. I understood English with ease since I understood the Arabic first, then I related the Arabic grammar into English grammar."

The learners agreed that translation as a classroom activity could promote their acquisition of vocabulary in a foreign language, and this was attained by translating Arabic word by word into English. This result is supported by Carreres (2006), who established that $93 \%$ of translation into English led to learning of vocabulary. Besides, translating Arabic word by word taught learners about English parts of speech. The learners linked parts of speech of Arabic words to English and learned their equivalents; the links they made are recognised as trans-language. This finding supports work by García (2009), who claims that trans-language allows bilingual learners to implement their entire linguistic repertoire from previous languages, enabling such learners to accurately comprehend the material. This method dealt with obstructions to these learners acquiring English, as it enabled them to comprehend English more easily.

\section{Untranslatable Arabic words}

On the other hand, the students also demonstrated their lack of knowledge in rendering the intended meaning of Arabic words into English. Some Arabic 
words were so culture-specific and comprehensive in meaning that the learners failed to select English words that had a similar meaning:

"Usually, my teacher reads the Arabic text first and gives vocabulary on the blackboard relating to the topic at that meeting. Sometimes, I translate Arabic language into English by myself. I often experienced difficulty in translation and, despite using a dictionary, I could not find the meaning of the Arabic words I looked for in the English language."

"My difficulty is that terms in Arabic cannot be translated into English. 'Zakat' cannot be translated as giving, nor can 'Hajj'. As far as I know, English natives are mostly unfamiliar with the words 'Hajj' and 'Zakat', so there is no equivalent words in the dictionary."

"The difficulty I had was that I did not know how to translate certain Arabic words. There are no appropriate translations of the words in English, meaning I did not find them in the dictionary. Because not all Arabic words can be translated into English, I still used the Arabic words in the English translation. For example, for 'dzuhur', meaning prayer, I could not find a word defined in this way. I could not use 'noon prayer' as the translation of 'dzuhur' because there are some prayers that can be done at noon besides 'dzuhur', so I just used 'dzuhur' in my translation."

"I often borrowed vocabularies from the source language, Arabic, for my translation then waited for the correct answers from my teacher. I did not know how to say them in English."

Students reported some Arabic words as untranslatable where they appeared incapable of identifying the equivalent lexical items in English. Arabic literature is often symbolic, subjective and expressive, and conveys implicit meanings that lead to text being untranslatable or non-translational. Since the Arabic textbooks are widely influenced by a certain culture, the intended meaning of the text relies on the culture of the source language that does not exist in English (Ya'qoub, 2013). Thus, it was hard to rewrite some passages, and they were not always represented in the target language due to a gap in cultural diversity. Because of this issue, some text might not be properly translated, as learners failed to select English words that had similar meanings.

Cultural dissimilarities between English and Arabic were hindrances to the students' translation process. Source-language words cannot be reproduced in an equivalent way to the target language, with attempts to do so sounding unnatural or strange. The learners stated that Arabic words were difficult to render in English. This difficulty was attributed to the lack of intercultural equivalence between Arabic and English making some Arabic words irreplaceable. Similarly, the process of translating Arabic into English must be sensitive to cultural differences; learners in this process tended to retain the Arabic words because they found no equivalent words from Western countries. 


\section{Arranging English translated words activity}

\section{Comprehending English grammar better}

Many of the students could understand English grammar better because they identified Arabic rules and compared them to English, enabling them to analyse those rules before applying them to translation tasks:

"I easily rearranged the Arabic words into English with the help of my comprehension of Arabic grammar. I compare as well as correlate grammar both in English and Arabic then looked for the similarities. My understanding of Arabic structure helped me to learn English structure."

"I like learning English through this Arabic theological book as I can learn how to translate. Although I said that I had difficulty in arranging the sentence, this book helped me understand English grammar because I had to arrange it."

"This Arabic textbook helped me learn English because before using this book, English was difficult for me, especially tenses. In Arabic, I know that a verb precedes the subject, then because I have to match the meaning of the Arabic sentence to the English sentence, I get the point that in English, subject precedes verb. The process of arranging subjects alongside verbs in Arabic and English did help me understand the English structure."

"I understood Arabic better than English because I have learnt Arabic for years and use it almost every day since joining the school two years ago. With English, I just learnt it in a formal school in the first year of senior high school and started it from a beginner level. Tenses are the part I think is difficult for me. If I did the same as what I did when I tried to master Arabic, I think I could master English as well.”

"Grammar between English and Arabic is so different. As I learnt the Arabic grammar first, I sometimes had difficulty in understanding English grammar. Then, I feel that it is a challenge that I should solve and from this I can understand English grammar. For example, the position of subjects and verbs in both languages are different. In Arabic, subject is placed after verb so the order in Arabic language is verb, subject and adverb. Whilst in English, subject is before verb so the structure is subject, verb and adverb."

"If in Arabic, this word is a predicate, I understand that the English translation of this word is a predicate as well. I can easily relate Arabic and English parts of speech."

Being able to use English tenses correctly

The students asserted that their difficulty in learning English tenses was solved when they knew in which contexts they should use certain English tenses. The context of the Arabic textbook gave them more clues in deciding the tense:

"I like learning English using this Arabic theological textbook. In English teaching and learning, I used to use an English book but found that the 
content was always about tenses or grammar. Comparatively, when I learn English using the Arabic theological textbook, I understand the use of tenses in English based on context. By translating Arabic into English, I can remember the English structure both in writing and speaking. I understand that this English grammar is used when I want to convey this message, such as present tense. Arranging sentences helps me understand English grammar."

"Overall, the use of the Arabic theological textbook helped me understand English better since I could use English grammar based on the context of the Arabic text, not only knowing and memorising the structure."

"After learning the English structure, I have to make sure of the correct English tense I should use in a sentence. Although tenses in English are my difficulty, this activity allowed me to learn a lot. English is hard for me, but when I have to match or translate the meaning of Arabic text into English, I understand tenses in English more."

"I learnt English grammar and memorised vocabulary since elementary school till I got bored, but now learning English using the Arabic theological textbook is like a new thing. When translating, I realise and understand, 'Oh, this is the function of this tense'. In the Arabic textbook, usually the tense used is past tense. I understood the structure of this tense."

Learners unconsciously carried out a deeper analysis into how an English sentence should be arranged. They identified Arabic rules and compared them with English, then analysed those rules before applying them to their translation task. This process is identified as trans-language, which describes multilingual speakers' competence in conveying their message in the form of varying languages within an integrated system (García, 2009). The learners' metalinguistic awareness improved owing to their noticing linguistic features when they practised several languages at the same time.

Knowing the translation method

The students further reported that they could indirectly understand the type of translation required, and used it to solve problems in translating the Arabic word by word:

"First I translated each word in the textbook. Sometimes, I took a sentence that could not be translated word by word then translated it using my own words, provided the meaning of the sentence was similar with the text."

"Learning English using this book is appealing. In my previous school, Ijust learnt how to translate an Arabic theological textbook into my mother tongue. Now, I learn how to translate Arabic into English as a foreign language. As I have mastered the content of the textbook, I can easily translate it into literal English. For example, 'kitabuh ahkamih thoharotih', 'kitabuh' is the book, 'ahkamih' is a law and 'thoharotih' is purification. So, the meaning of 'kitabuh ahkamih thoharotih' is 'this chapter explains about purification'." 
"I prefer learning English using this Arabic theological textbook. This book is much more challenging for me. It would be amazing if I could translate Arabic text into English. Although it is difficult, it attracts me to translate the meaning from Arabic to English."

"Now, I know how to translate a language to another one. Initially, I did not know how to read the content of this Arabic textbook in English. When I learnt English in formal school, I only knew how to arrange sentences in English."

"Now I have understood the meaning of the textbook, I can easily arrange the English translation of the text. If I have not comprehended the content of the text, I would face difficulty in translating it."

"Each word in Arabic cannot be translated into English, so I just conclude the meaning of the words in a sentence. Although I have learnt English tenses, I still get confused as I rarely rearrange or make English sentences."

Difficulty in deciding the tense in English

However, some students commented that they could not rearrange the English translated words well. Although they had already learnt the rules of English, they still found it difficult to use them, as that their understanding of Arabic rules interfered with their English learning:

"I have never translated an Arabic book into English. Grammar between Arabic and English are different. Each word in Arabic cannot be translated into English, so I just conclude the meaning of the words in a sentence. Although I have learnt English tenses, I still get confused as I rarely rearrange or make English sentences."

"If I face confusion in arranging the English words into a good English sentence, I look at my book in which I can find the structure of certain tenses. I add articles and rearrange the words like adding an adjective before a noun."

"I was more confused when translating the Arabic words into English because I did not know what tenses I should use in the sentence. I was afraid that the English structure was wrong and it tended to imitate Arabic structure. Maybe, this is because I learnt English grammar for two months just before joining this activity (learning English using an Arabic theological textbook). In Arabic, verb precedes subject, but English is different."

"If I had difficulty in arranging my translated words, I looked at my own notes about English grammar in my book, looked at the example of the tense in the book and followed the pattern, though I was still confused."

"My difficulty is in arranging the words. If I did not understand the meaning of the Arabic sentence, I experienced difficulties in translating it into 
English and otherwise. I asked my friends whom I think know more than me, if I had difficulty."

Difficulty with the English passive voice

Furthermore, the students often struggled with rearranging the Arabic text into passive English. They asserted that the linguistic rules of English and Arabic are very different, and they found it confusing when asked to change content from the Arabic textbook into passive sentences in English:

"In English, the subject is in the first sentence. In Arabic, the subject usually does not appear until sometime after the verb. They are so different. In English grammar, I do not know how to make a passive voice in the present perfect tense."

"The obstacle I faced was when changing a sentence of active voice in Arabic into passive voice in English. I usually forget 'to be' in English, which is why I think the passive voice is difficult for me. I am afraid I make mistakes in rearranging and reading the English sentence."

These problems in translation happen where the two languages are distinct in terms of meaning, letters and the way the letters are arranged into phrases as well as sentences. This is called the script-dependent hypothesis, in which the problems caused are an effect of language differences (Abu-Rabia and Siegel, 2002). In fact, Arabic and English have completely discrepancy. English begins a sentence with a subject followed by a verb. Conversely, Arabic sentences are formed as verb-subject-complement. It seems that these learners' understanding of Arabic rules has interfered with their English learning.

\section{Small talk interview}

Speaking English more fluently

After a pairing exercise, participants stated that asking their partner questions about the content of the Arabic textbook helped them to speak English fluently because the content was relevant to their own culture, and they could practise speaking more. Moreover, they affirmed that letters were pronounced in the same way in Arabic and English, even though the orthography of both languages was different:

"I read the Arabic sentence first, then read the translation that I have made. Speaking using this book teaches me how to pronounce a new word. I like learning English when I translate the Arabic word by word and pronounce it."

"My friend and I asked many questions relating to the topic respectively to measure our understanding of the material in English. My understanding towards the book gave me more material to be asked about by my friend."

"If my friend asked me a question, I could learn English from the questions being asked, for example, my friend asked 'What is this? What is the 
position of this word? Why is it called ...? Why do you say it is...?'. I imitated the way he used English."

"After the teacher explained then corrected our translation work, my friend and I questioned each other to measure our understanding. Usually we discussed the content of the textbook using English. Through this media, I know how to ask questions in English."

"I didn't understand English at first, but owing to learning English using this Arabic textbook, I can understand English grammar and speak English because my comprehension of Arabic grammar so the content of this book helped me a lot."

"Some letters in English are said the same the way I pronounce Arabic words, for example, the letter 'th' can be pronounced / $\theta /$ or / J/. In Arabic, there are letters that have the same pronunciation to them, such as $ث$ (one Arabic letter)."

This study supports the hypothesis of cross-language transfer, which addresses the phonological awareness of bilinguals (Abu-Rabia and Segel, 2002). Even if distinct languages have different orthographies, the learners could still correlate the same pronunciation between Arabic and English. Another major aspect which enabled the students to learn English better through the Arabic textbook was the matched context of English material, as it was relevant to the learners' own culture. Since the learners understood the media, they expressed their ideas in English easily, without anxiety, and became more engaged in learning English (Liao, 2006). Integrating the Islamic message into English language teaching can help learners in Islamic schools to comprehend the language, as it reflects the culture in which they live.

Moreover, trans-language proved beneficial in the last classroom activity where the participants reported that asking their partners questions about the content of the Arabic textbook enabled them to speak English more fluently. Trans-language was also demonstrated through procedural knowledge in discussion, clarification and task completion. The learners were able to comprehend the message from the text more easily and increase their motivation as well as participation in class, as trans-language focuses on function rather than form (Lin and Martin, 2008; Arthur and Martin, 2006; García, 2009; Creese and Blackledge, 2010).

\section{Difficulty in pronouncing English}

A few students realised that they could not speak English well due to their confusion regarding letters with different pronunciation in English:

"I did not know how to pronounce the words in English which have similar sounds, such as later, letter, leather, leader and paper, pepper. My friend often laughed at me when I tried to pronounce them."

"I asked the teacher if I did not know how to arrange the English words like leather, letter, later, leader as I usually mistyped and mispronounced them." 
Further, a few students realised that they could not speak English well due to their confusion regarding differing letter pronunciations in English. This problem is also a result of script-dependency, according to Abu-Rabia and Siegel's work on the hypothesis (2002). Clearly, English and Arabic have distinct orthographies in which English uses the Roman writing system, rather than the Arabic. Arabic has a one-to-one relationship between its grapheme and phoneme (that is, learners can read as well as pronounce Arabic words as they have been written or spelt), but English does not. In addition, Arabic and English are syntactically different. In English, the grammatical subject in a sentence precedes the verb, but in Arabic, the opposite is true. Additionally, the Arabic system is read from right to left and English vice-versa.

The existence of this problem is supported by the script-dependent hypothesis (Abu-Rabia and Siegel, 2002; Abdul Haq, 1982; Zughoul, 1984). Owing to dissimilar orthographies, some errors in learning English occur, particularly in writing and spelling. Furthermore, Arabic-speaking learners of English tend to miss English vowels, but recognise consonants well. These errors might arise because of lexical processes as well as phonological distinctions between Arabic and English. Through many studies, Abdul Haq (1982) and Zughoul (1984) emphasise that Arab learners of English face serious lexical, syntactical and phonological errors while communicating in English.

Interestingly, the concept of trans-language, which often obstructs learners of second or foreign languages, did not appear in responses in this study. García (2009) assumed that the disadvantage of trans-language was that it led learners to prefer using one language only and distracted their selection of which language to utter. This was owing to the existence of a linguistic hierarchy within learners, who ascribed superiority to one language over another. In addition, Cummin's (1979) theory - that learners' difficulties in learning a second language (in this case English) were the same as those faced in their first language (in this case Arabic) - the linguistic interdependent hypothesis, did not occur in this study. As previously stated, the respondents had already mastered Arabic in both its rules and in communication, but a strong ability in Arabic did not mean that the learners did not face any difficulty.

\section{CONCLUSION}

The results show that through the Arabic textbook, the learners could improve their English vocabulary, understand parts of speech within the English translated words, use English grammar better - especially tenses - learn how to translate, pronounce English words and speak English more fluently as they understood the content in the book. These benefits were thanks to the learners' trans-language excursions. On the other hand, the results indirectly highlight obstacles in using an Arabic textbook, even where learners have mastered the content. These struggles included their lack of knowledge in converting the meaning of Arabic words into English due to culture-specific elements. Learners also had trouble determining which tense in English matched an Arabic sentence, constructing a sentence in the English passive voice, and pronouncing English words. 
The findings of this research relate to successes and obstacles, and are aimed at providing good information to future research into how to solve these obstacles. Besides, an experimental study in which one group of students uses an Arabic textbook, while another group does not, might provide effective analysis to compare and research textbooks' contribution to the improvement of certain skills. Going further, an analysis is recommended into how English language can be acquired through Arabic.

\section{REFERENCES}

Abdul Haq, F. (1982). An analysis of syntactic errors in the composition of jordanian secondary students (unpublished master thesis). Jordan. Yarmouk University.

Abu-Rabia, S., \& Siegel, L. S. (2002). Reading, syntactic, orthographic, and working memory skills of bilingual Arabic-English speaking Canadian children. Journal of psycholinguistic research, 31(6), 661-678.

Ali, A., Brakhw, M. A., Nordin, M. Z. F. B., \& ShaikIsmail, S. F. (2012). Some linguistic difficulties in translating the holy Quran from Arabic into English. International Journal of Social Science and Humanity, 2(6), 588590 .

Arthur, J., \& Martin, P. (2006). Accomplishing lessons in postcolonial classrooms: comparative perspectives from Botswana and Brunei Darussalam. Comparative Education, 42(2), 177-202.

Borg, S. (2015). Teacher cognition and language education: Research and practice. London, UK: Bloomsbury Publishing.

Carreres, A. (2006.) Strange bedfellows: Translation and language teaching, the teaching of translation into L2 in modern languages degree; uses and limitations. Cambridge, UK: Cambridge University Press.

Cheung, C. (2001). The use of popular culture as a stimulus to motivate secondary students' English learning in Hong Kong. ELT Journal, 55(1), 55-61.

Creese, A., \& Blackledge, A. (2010). Translanguaging in the bilingual classroom: A pedagogy for learning and teaching? The modern language journal, 94(1), 103-115.

Cummins, J. (1979). Linguistic interdependence and the educational development of bilingual children. Review of educational research, 49(2), 222-251.

García, O. (2009). Education, multilingualism and translanguaging in the 21st century. Multilingual Education for Social Justice: Globalising the local. New Delhi: Orient Blackswan.

Halliday, M., Matthiessen, C. M., \& Matthiessen, C. (2014). An introduction to functional grammar. London, UK: Routledge.

Hancock, M. \& Algozzine, B. (2006). Doing case study research. New York: Teachers College Press. 
Liao, P. (2006). EFL learners' beliefs about and strategy use of translation in English learning. RELC Journal, 37(2), 191215.

Lin, A. M. Y., \& Martin, P. (2005). (Eds.). Decolonisation, globalisation: Language- in-education policy and practice. Clevedon, UK: Multilingual Matters.

Maynard, T., \& Furlong, J. (1995). Learning to teach and models of mentoring. Issues in mentoring, 10-24.

Nolasco, R., \& Arthur, L. (1995). Large classes. Hemel Hempstead: Phoenix ELT.

Nunan, D. (1993). From learning-centeredness to learner-centeredness. Applied Language Learning, 4, 1-18.

Punch, K. F. (2013). Introduction to social research: Quantitative and qualitative approaches. London, UK: Sage.

Schäffner, C. (Ed.). (2002). The role of discourse analysis for translation and in translator training. Clevedon, UK: Multilingual matters.

Tomlinson, B. (2005). The future for ELT materials in Asia. Electronic Journal of Foreign Language Teaching, 2(2), 5-13.

Ya'qoub, S. H. A. (2013). Audience types in translating humor in TV shows from English into Arabic (unpublished master thesis). An-Najah National University.

Zainab, H. (2010). Strategies and motivations in translated animated films: Defoe's animated films as a case study (unpublished master thesis in translation and applied linguistics), an- Najah National University, Nablus, Palestine.

Zughoul, M. and L. Taminian. (1982). The linguistic attitude of Arab university students: factorial structure and intervening variables. The International Journal of the Sociology of Language. 50, 155-179. 